\title{
Pesquisa Clínica e Câncer
}

https://doi.org/10.32635/2176-9745.RBC.2021v67n3.2370

\author{
Clinical Research and Cancer \\ Investigación Clínica y Cáncer
}

\section{Daniel Cohen Goldemberg'}

O primeiro ensaio clínico do qual se tem ciência data de 600 anos antes da Era Comum, com registro no Velho Testamento, caracterizando-se hoje em dia como um estudo-piloto ${ }^{1}$. A Europa é o continente mais conectado em termos de realização de pesquisa clínica no mundo², e a Organização Europeia para Tratamento e Pesquisa do Câncer (EORTC), fundada apenas em 1962, desde então, conduziu mais de 1.400 ensaios clínicos por intermédio de sua rede, que conta com mais de 5.300 pesquisadores e quase 400 instituiçóes distribuídas por 37 países, sempre com o mesmo objetivo de melhora da qualidade de vida e sobrevida dos pacientes que apresentam neoplasias malignas ${ }^{3}$. Já em 2008, o Grupo Cooperativo Latino-americano de Oncologia (LACOG) foi fundado por oncologistas com uma grande valorização da interdisciplinaridade e inclui em seu quadro pesquisadores com inúmeras especializações na área de saúde, inclusive fora da medicina. Neste contexto, o desafio se faz ainda maior, com o objetivo de proporcionar tratamento oncológico de excelência em países de baixa e média rendas

Antes que qualquer ensaio clínico seja sequer enviado ao Comitê de Ética pertinente, deve ser desenvolvido a partir de uma pergunta científica relevante, apresentar um desenho de estudo e ferramentas de análise apropriados, e depender de uma base de dados de alta qualidade que possa ser compreendida por qualquer investigador e reanalisada, caso necessário. Quanto aos fundamentos da pesquisa clínica, o que também se aplica em oncologia, fazem-se essenciais a definição de uma população-alvo, dos grupos de exposição ou intervenção, comparaçôes e desfechos a serem avaliados 5 .

Técnicas de biologia molecular cada vez mais avançadas, como espectrometria de massa, análises ômicas, sequenciamento de nova geração e análises de célula única, auxiliam sobremaneira o avanço das pesquisas clínicas de uma forma geral ${ }^{5}$ e não é diferente para os pacientes oncológicos. O uso de DNA tumoral circulante é outro exemplo do uso das novas tecnologias cada vez mais em expansão. Neste contexto, ensaios epigenéticos avançam a passos largos, com pesquisas inovadoras que podem ser úteis nos estudos envolvendo câncer e na prática clínica. Alguns exemplos de aplicação em pesquisa clínica e câncer são a análise de metilação de DNA, que pode contribuir com o processo de carcinogênese nos casos em que silencia genes supressores tumorais, e a genotipagem do DNA tumoral circulante livre de células (cfDNA), já com iminente aplicação clínica em câncer de pulmão não pequenas células (CNPC) .

A evolução das técnicas moleculares permitiu a caracterização de novos tumores, como no caso das neoplasias malignas de glândulas salivares. A equipe da pesquisa clínica do Instituto Nacional de Câncer José Alencar Gomes da Silva (INCA) evidenciou um tumor previamente nunca diagnosticado pela patologia da instituição: o carcinoma secretor (CS) de glândulas salivares. A tendência é que, com a evoluçáo dos estudos clínicos, patológicos e moleculares, a categoria de carcinoma sem outra especificação (SOE) esteja fadada à extinçâo, visto que cada vez mais se torna possível entender esses tumores mais raros mediante a identificação de genes de fusão, como o ETV6-NTRK3, observado no CS, normalmente, cujos pacientes podem se beneficiar de terapia-alvo molecular?

A rede globalizada de pesquisa mostra sua relevância nos ensaios clínicos, que têm se apresentado cada vez mais frequentes, aumentando não somente a representatividade estatística, como também a variabilidade genética dos pacientes e tumores estudados ${ }^{2}$. No INCA, há atualmente a participação de pesquisadores com a inclusão de pacientes atendidos e tratados na instituição em aproximadamente 150 ensaios clínicos multicêntricos.

Vale ressaltar que, atualmente, os cuidados dos pacientes oncológicos devem ser redobrados, em decorrência da pandemia pelo Sars-CoV-2, não somente na assistência como em pesquisa clínica, uma vez que parece haver um risco maior de contrair covid-19 com uma taxa de letalidade mais elevada do que na população em geral ${ }^{8}$. E, em última análise, o constante avanço na pesquisa básica e a crescente globalização da pesquisa clínica devem servir de estímulo

'Divisão de Pesquisa Clínica e Desenvolvimento Tecnológico do Instituto Nacional de Câncer José Alencar Gomes da Silva (INCA). Rio de Janeiro (RJ), Brasil. Honorary Oral Medicine Senior Lecturer - University College London (UCL). Londres, Reino Unido. Latin American Cooperative Oncology Group (LACOG) - Head and Neck. E-mail: daniel.cohen@inca.gov.br. Orcid iD: https://orcid.org/0000-0002-0089-1910 
para que os desafios da pesquisa translacional em câncer se transformem em oportunidades ${ }^{9}$, por meio de ensaios clínicos que permitam o aumento da sobrevida dos pacientes com câncer, com o desenvolvimento de novos tratamentos antineoplásicos que apresentem menos efeitos colaterais.

\section{REFERÊNCIAS}

1. Nakamura R, Khawaja F, Castillo-Saavedra L, et al. Basics of clinical research: introduction to clinical research. In: Fregni F, Illigens BMW, editors. Critical thinking in clinical research: applied theory and practice using case studies. Oxford, UK: Oxford University Press; 2018. p. 3-25. doi: https://doi.org/10.1093/med/9780199324491.003.0001

2. Richter TA. Clinical research: a globalized network. PLoS One. 2014;9(12):e115063. doi: https://doi.org/10.1371/ journal.pone.0115063

3. Broes S, Saesen R, Lacombe D, et al. Past, current, and future cancer clinical research collaborations: the case of the European Organisation for Research and Treatment of Cancer. Clin Transl Sci. 2021;14(1):47-53. doi: https://doi. org/10.1111/cts. 12863

4. Barrios $\mathrm{CH}$. The good example: potential of clinical research to expand quality care in low- and middle-income countries. Am J Bioeth. 2016;16(6):22-3. doi: https://doi.org/10.1080/15265161.2016.1170246

5. Hoshino J. Introduction to clinical research based on modern epidemiology. Clin Exp Nephrol. 2020;24(6):491-9. doi: https://doi.org/10.1007/s10157-020-01870-3

6. Ossandon MR, Agrawal L, Bernhard EJ, et al. Circulating tumor DNA assays in clinical cancer research. J Natl Cancer Inst. 2018;110(9):929-34. doi: https://doi.org/10.1093/jnci/djy105

7. Alves LDB, Melo AC, Lima Araujo LH, et al. Secretory carcinoma of salivary glands at the National Cancer Institute: a 20-year retrospective clinical, pathological, immunohistochemical and molecular study. Oral Oncol. 2021;117:105198. doi: https://doi.org/10.1016/j.oraloncology.2021.105198

8. Thuler LCS, Melo AC. Sars-CoV-2/Covid-19 em pacientes com câncer. Rev Bras Cancerol. 2020;66(2):e-00970. doi: https://doi.org/10.32635/2176-9745.RBC.2020v66n2.970

9. Stefanoff G. Pesquisa translacional em câncer: desafios e oportunidades. Rev Bras Cancerol. 2021;67(1):e-001768. doi: https://doi.org/10.32635/2176-9745.RBC.2021v67n1.1768 